\title{
Característica química do solo e o crescimento do Eucalyptus grandis fertilizado com efluente da indústria de refino de óleo vegetal
}

\author{
Paulo Fortes Neto ${ }^{1}$; Ana Aparecida da Silva Almeida ${ }^{1}$; Nara Lúcia Perondi Fortes ${ }^{1}$; \\ Eliana Maria Araújo Mariano Silva ${ }^{1}$ \\ ${ }^{1}$ Universidade de Taubaté - UNITAU \\ Estrada Municipal Dr. José Luiz Cembranelli, 5.000 - 12080-010 - Taubaté - SP, Brasil \\ paulofortes.neto@gmail.com \\ anasilva@unitau.br \\ nara_fortes@uol.br \\ eliote.bio@ig.com.br
}

\begin{abstract}
The objectives of this study were to characterize chemically and quantify the nutrient soil input with vegetable oil industrial treated effluent. For effluent characterization, chemical and microbiological analyses were carried out. The experimental design consisted of randomized blocks with five treatments (T1, mineral fertilization; T2, effluent $0 \mathrm{~m}^{3} \mathrm{ha}^{-1}$; T3, effluent $11 \mathrm{~m}^{3} \mathrm{ha}^{-1}$; T4, effluent $22 \mathrm{~m}^{3} \mathrm{ha}^{-1}$ and T5, effluent $33 \mathrm{~m}^{3} \mathrm{ha}^{-1}$ ) and four replicates. Soil samples were collected $(0-20 \mathrm{~cm}$ layers $) 120$ day after effluent application. The applications resulted in the increase of nutrients $(\mathrm{P}, \mathrm{Ca}$ and $\mathrm{Mg}$ ) and $\mathrm{Na}$ that were added to the soil. The treatment with mineral fertilization and effluent proportion (T1) showed a higher plant growth rate
\end{abstract}

Palavras-chave: effluent, nutrients, sodium, eucalypt, forest, efluente, nutrientes, sódio, eucalipto, floresta.

\section{INTRODUÇÃO}

O reuso agrícola de efluentes de esgotos tratados destaca-se como uma alternativa econômica para disposição ambiental desse resíduo, pois aumenta a fertilidade do solo e fornece nutrientes para as plantas. Constitui também, uma forma de minimizar o impacto causado pelo fósforo e pelo nitrogênio nos efluentes de esgoto, quando lançados em corpos receptores (Asano et al., 1996; Souza, et al., 2009). Apesar desses benefícios, a prática não é isenta de riscos, principalmente devido à presença de determinados constituintes característicos do esgoto doméstico, como, por exemplo, o sódio e os organismos patogênicos que são prejudicais ao solo, às plantas e, consequentemente, ao ser humano (Balks et al., 1998; Gomes, et al., 2009).

A maioria dos estudos apresenta resultados verificados com hortaliças, grãos, forrageiras e cana de açúcar, sendo raros resultados com culturas de reflorestamento (Faria et al., 2003; Cunha, et al., 2005; Biscaro, et al., 2008; Leal,et al., 2009).

Com base no exposto, o presente projeto teve como objetivo avaliar o aporte de nutrientes e sódio e, também, o crescimento de Eucalyptus grandis, após a aplicação do efluente no solo.

\section{MATERIAL E MÉTODOS}

O estudo foi realizado em um Argissolo Vermelho-Amarelo distrófico (Embrapa, 1999), com as seguintes características: $\mathrm{pH}\left(\mathrm{CaCl}_{2}\right)=4,1$; matéria orgânica $=15 \mathrm{~g} / \mathrm{dm}^{3}$; fósforo disponível $=4,0 \mathrm{mg} / \mathrm{dm}^{3} ;$ potássio $=1,0 \mathrm{mmol}_{\mathrm{c}} / \mathrm{dm}^{3} ;$ cálcio $=3,5 \mathrm{mmol}_{\mathrm{c}} / \mathrm{dm}^{3} ;$ magnésio $=1,0$ mmol ${ }_{\mathrm{c}} / \mathrm{dm}^{3}$; hidrogênio + alumínio $=45 \mathrm{mmol}_{\mathrm{d}} / \mathrm{dm}^{3} ;$ sódio $=0,3 \mathrm{mmol}_{\mathrm{d}} / \mathrm{dm}^{3} ;$ soma de bases $=$ 
$5,5 \mathrm{mmol}_{\mathrm{c}} / \mathrm{dm}^{3} ;$ capacidade de troca de cátions $=49,0 \mathrm{mmol}_{\mathrm{c}} / \mathrm{dm}^{3} ;$ saturação de bases $=12$ $\mathrm{mmol}_{\mathrm{c}} / \mathrm{dm}^{3}$ e a condutividade elétrica $=0,14 \mathrm{dS} / \mathrm{m}$.

O efluente utilizado tem origem no processo de extração do ácido graxo da borra oleosa e a sua composição química e microbiológica estão apresentadas na Tabela $\mathbf{1}$.

Tabela 1. Características químicas e microbiológicas do efluente proveniente da extração do ácido graxo

\begin{tabular}{lc}
\hline Atributos & R esultados \\
\hline Umidade (\%) & 84,3 \\
pH & 6,6 \\
Condutividade (dS/m) & 25,9 \\
Índice salino (\%) & 13,5 \\
Razão de Adsorção de Sódio (RAS) & 12,08 \\
Dureza (mg CaCO $/ \mathrm{L})$ & 33.744 \\
Cloreto (g de Cl'/L) & 0,9 \\
Matéria orgânica total (g de C/L) & 22,4 \\
Carbono orgânico (\%) & 1,5 \\
Nitrogênio Kjeldahl (g de N/L) & 4,1 \\
Arsênio (mg de As/L) & $<0,5^{(2)}$ \\
Cádmio (mg de Cd/L) & $<0,5^{(2)}$ \\
Cálcio (g de Ca/L) & 14,7 \\
Chumbo (mg de Pb/L) & $<0,5^{(2)}$ \\
Cobre (mg de Cu/L) & $<0,5^{(2)}$ \\
Cromo (mg de Cr/L) & $<0,5^{(2)}$ \\
Enxofre (g de S/L) & 4,2 \\
Fósforo solúvel em ácido cítrico (g de P/L) & 3,0 \\
Magnésio (g de Mg/L) & 11,6 \\
Mercúrio (mg de Hg/L) & $<0,5^{(2)}$ \\
Níquel (mg de Ni/L) & $<0,5^{(2)}$ \\
Selênio (mg de Se/L) & $<0,5^{(2)}$ \\
Sódio (mg de Na/L) & 8.506 \\
Zinco (mg de Zn/L) & 0,6 \\
Soma de Macro-primários N + P (\%) & 0,71 \\
Soma de Macro-secundários Ca + Mg + S (\%) & 3,0 \\
Escherichia coli (NMP/100ml) & 0,003 \\
Salmonella sp. (NMP/100ml) & $A u s e n t e$ \\
Ovos viáveis de Helmintos (Ovos/100ml) & 0,004 \\
\hline
\end{tabular}

Os tratamentos foram calculados tendo como referência a quantidade de fósforo existente no efluente e a necessidade para atender a cultura do eucalipto.

O experimento foi distribuído no campo em um delineamento de blocos casualizados com cinco tratamentos (T1, efluente $0 \mathrm{~m}^{3} \mathrm{ha}^{-1}$; T2, adubação mineral; T3, efluente $11 \mathrm{~m}^{3} \mathrm{ha}^{-1}$; T4, efluente $22 \mathrm{~m}^{3} \mathrm{ha}^{-1}$ e T5, efluente $33 \mathrm{~m}^{3} \mathrm{ha}^{-1}$ ) e quatro repetições.

No tratamento com fertilização mineral, foram utilizadas $120 \mathrm{~kg} \mathrm{ha}^{-1} \mathrm{de} \mathrm{N}, 80 \mathrm{~kg} \mathrm{ha}^{-1} \mathrm{de}$ $\mathrm{P}_{2} \mathrm{O}_{5}$ e $180 \mathrm{~kg} \mathrm{ha}^{-1}$ de $\mathrm{K}_{2} \mathrm{O}$, conforme Raij et al. (1997).

As amostras de terra foram coletadas aleatoriamente nas entrelinhas das parcelas, com o auxílio de um trado introduzido até a camada de $0-20 \mathrm{~cm}$ de profundidade. As amostras foram coletadas 120 dias após o plantio do Eucalyptus grandis. 
Foram analisados $\mathrm{pH}$ em $\mathrm{CaCl}_{2}$ 0,01 mol L ${ }^{-1}$, carbono orgânico, fósforo disponível, cálcio, magnésio, potássio, sódio, alumínio trocável, capacidade de troca de cátions, saturação por bases e condutividade elétrica, conforme metodologia preconizada Raij et al. (2001).

A determinação da altura das plantas foi realizada no $30^{\circ}$ e $120^{\circ}$ dia, após o plantio das mudas de eucalipto.

Os resultados foram submetidos à análise da variância com aplicação do teste $\mathrm{F}$ e as médias comparadas entre si pelo teste de Tukey a 5\%.

\section{RESULTADO E DISCUSSÃO}

\section{Característica química do solo}

A quantidade de fósforo no solo aumentou significativamente somente com a aplicação do efluente na dose de $33 \mathrm{~m}^{3} \mathrm{ha}^{-1}$ quando comparado com os tratamentos testemunha, adubação mineral e as doses de 11 e $22 \mathrm{~m}^{3} \mathrm{ha}^{-1}$ de efluente (Figura 1). Os teores de fósforo no solo das parcelas fertilizadas com as doses do efluente variaram entre 15,19 e $54 \mathrm{mg} \mathrm{dm}^{-3}$ respectivamente para as doses de 11,22 e $33 \mathrm{~m}^{3} \mathrm{ha}^{-1}$ de efluente. O incremento de fósforo foi devido ao fornecimento deste elemento pelo próprio efluente, pois nesses tratamentos não foram adicionados fertilizantes fosfatados. Resultados similares, também foram observados por Sandri, et al. (2009) em solos irrigados com água resíduárias provenientes do tratamento de esgoto.

Na Figura 1 estão apresentados os resultados de cálcio e magnésio no solo das áreas com adubação mineral e as doses do efluente, nota-se que os valores de cálcio aumentaram significativamente nas parcelas com a aplicação de 22 e $33 \mathrm{~m}^{3} \mathrm{ha}^{-1}$. Esses resultados sugerem que o cálcio está solúvel no efluente ao contrário do que é observado geralmente nos efluentes de esgoto domésticos no qual o cálcio é precipitado pelo sulfato (Jnad et al., 2001).

As dosagens do efluente promoveram um incremento nos teores de sódio no solo, sendo que a dose $11 \mathrm{~m}^{3} \mathrm{ha}^{-1}$ foi a que proporcionou a menor elevação de sódio (Figura 2). Essa tendência progressiva de sódio no solo pode ter ocorrido porque os teores de sódio presentes no efluente tenham sido superiores à capacidade de absorção pelo eucalipto, promovendo assim o acúmulo desse íon no solo (Leal et al., 2009).

\section{Altura das plantas}

Os valores da altura das plantas de eucalipto fertilizadas com adubação mineral e efluentes estão apresentados na Figura 3, verifica-se que a adição do efluente proporcionou aumentos significativos no desenvolvimento das culturas entre os tratamentos. Comparando os valores da altura das plantas entre 30 e 120 dias, observa-se que, nesse período, as mudas do tratamento testemunha cresceram cerca de $32 \mathrm{~cm}$ e as mudas dos tratamentos com o efluente nas doses de 22 e $33 \mathrm{~m}^{3} \mathrm{ha}^{-1}$ apresentaram um crescimento de 75,74 e $93 \mathrm{~cm}$, respectivamente. As mudas com adubação mineral apresentaram um crescimento de $92 \mathrm{~cm}$, o interessante é que esse valor foi igual ao obtido com a dose 3P. Esses resultados refletem a resposta do eucalipto à adubação mineral e aplicação do efluente na dosagem de 11, 22 e 33 $\mathrm{m}^{3} \mathrm{ha}^{-1}$. 


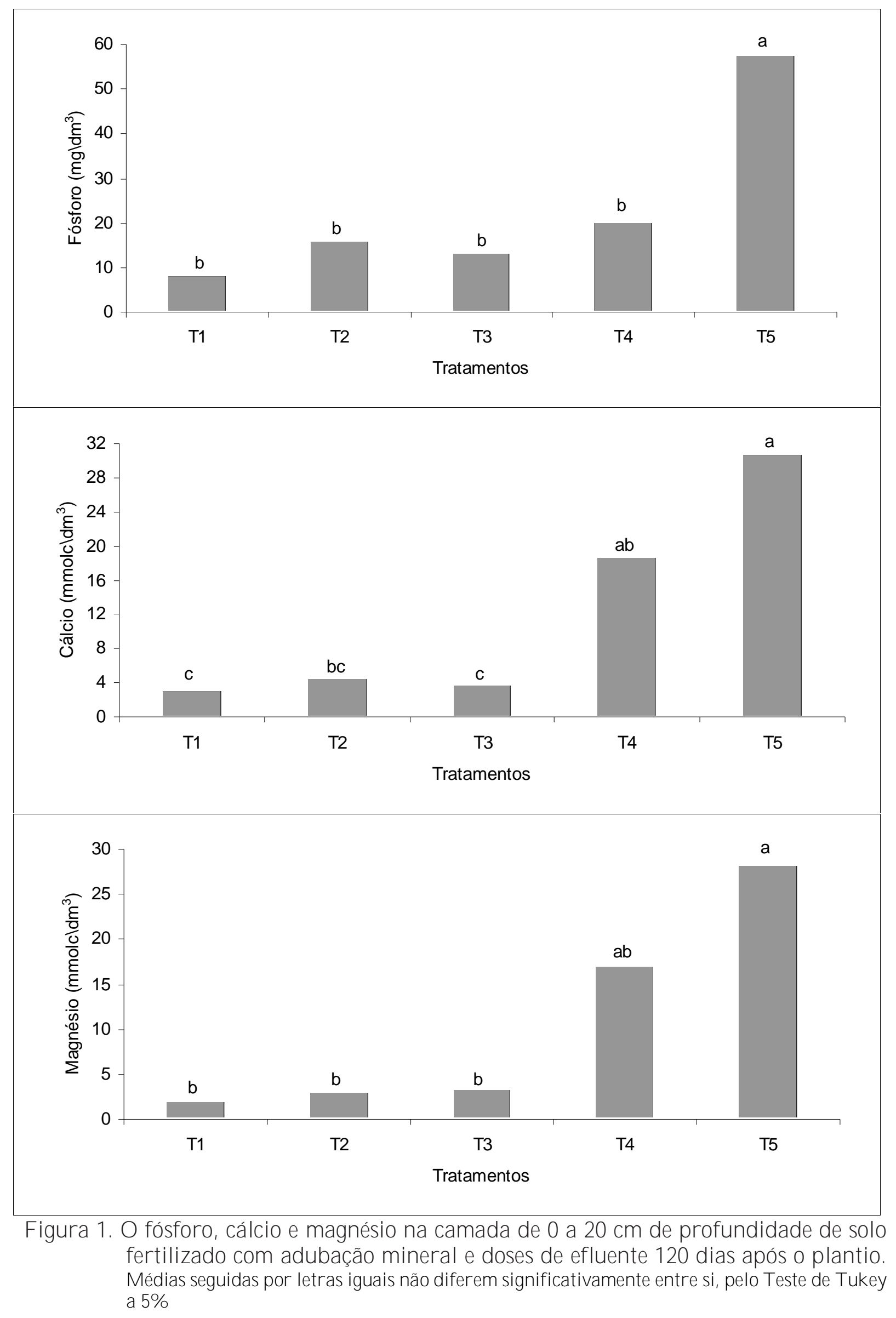




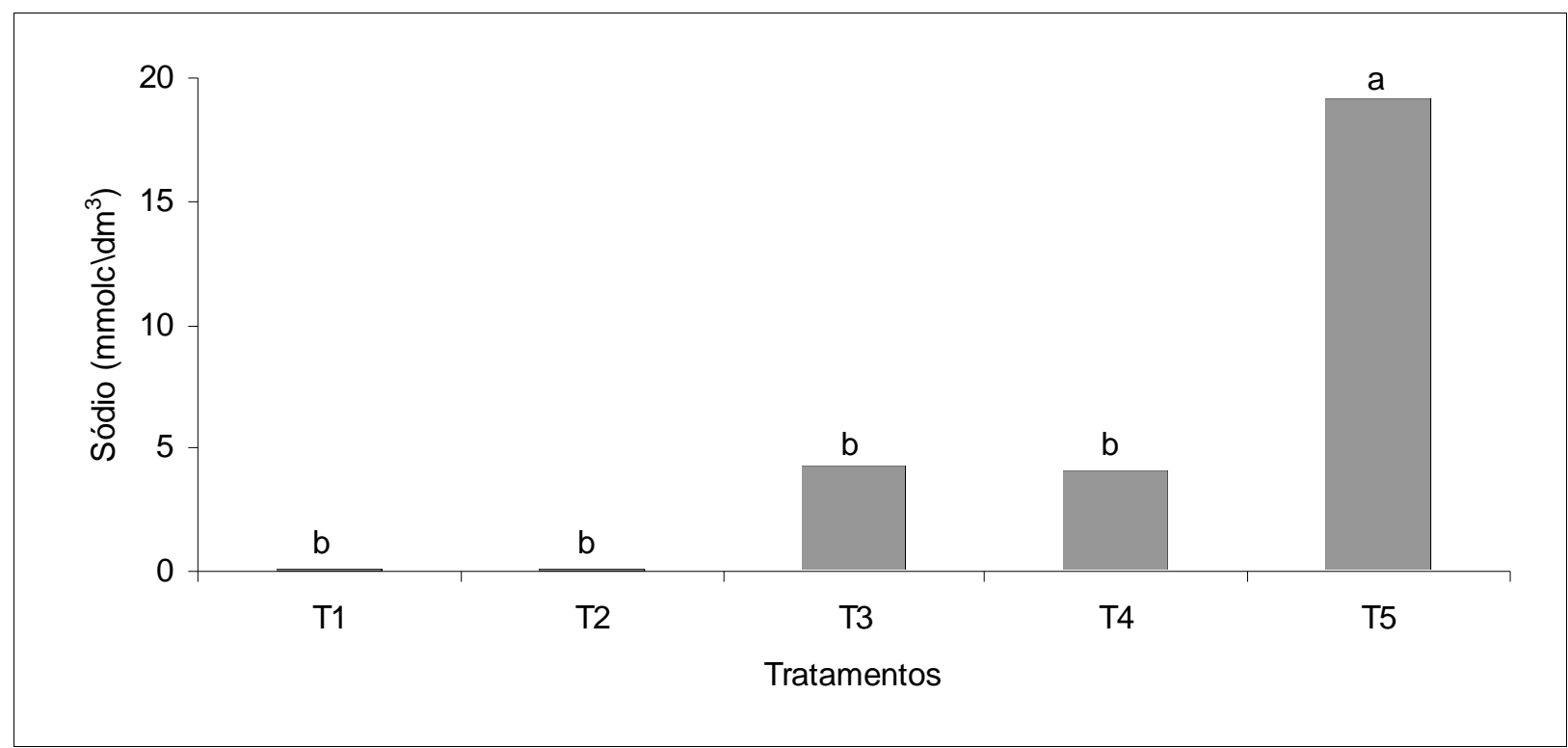

Figura 2. 0 sódio na camada de 0 a $20 \mathrm{~cm}$ de profundidade de solo fertilizado com adubação mineral e doses de efluentes 120 dias após o plantio. Médias seguidas por letras iguais não diferem significativamente entre si, pelo Teste de Tukey a 5\%.

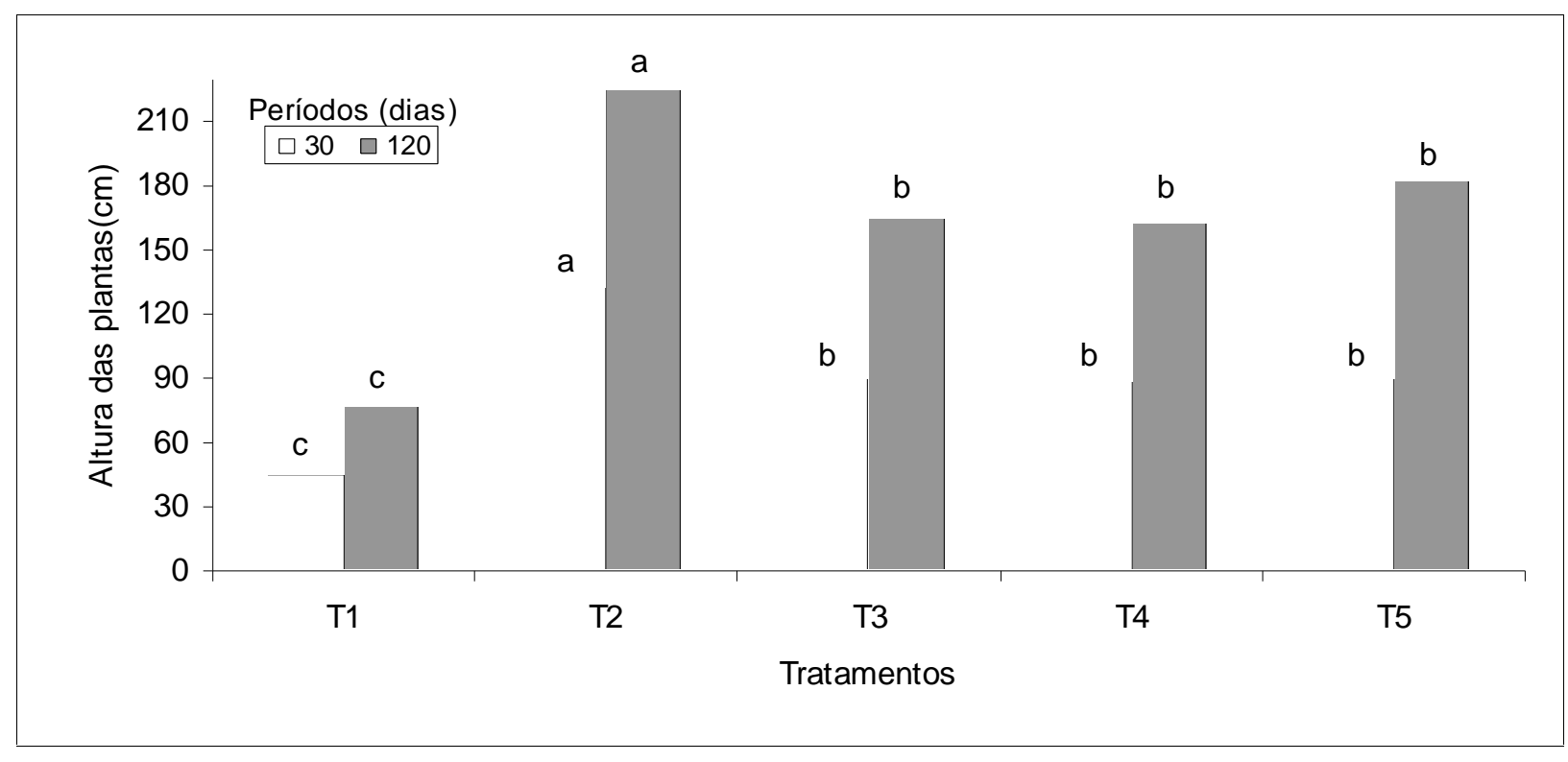

Figura 3. Altura da parte aérea das plantas de eucalipto aos 30 e 120 dias após a aplicação do efluente em um solo fertilizado com adubação mineral e efluente nas dosagens de $T 1\left(11 \mathrm{~m}^{3} \mathrm{ha}^{-1}\right), \mathrm{T}_{2}\left(22 \mathrm{~m}^{3} \mathrm{ha}^{-1}\right)$ e $\mathrm{T} 3\left(33 \mathrm{~m}^{3} \mathrm{ha}^{-1}\right)$. Médias seguidas por letras iguais não diferem significativamente entre si, pelo Teste de Tukey a $5 \%$. 


\section{CONCLUSÕES}

- O efluente proporcionou aumento nos teores de sódio no solo.

- A dose de $33 \mathrm{~m}^{3} \mathrm{ha}^{-1}$ (T5) elevou os teores de fósforo, cálcio e magnésio no solo.

- O efluente em todas as dosagens favoreceu o desenvolvimento do Eucalyptus grandis.

\section{LITERATURA CITADA}

Assano, T.; Maeda, M.; Takaki, M. Wastewater reclamation and reuse in Japan: overview and implemention examples. W ater Science Tecnology, Oxford, v.34, n.1. p.219-226, 1996.

Balks, M.R.; Bond, W.J.; Smith, C.J. Effects of sodium accumulation on soil properties under an effluentirrigated plantation. Australian J ournal of Soil Research. Melbourne, v.36, n.5, p.821-830, 1998.

Biscaro, G.A.; Machado, J.R.; Tosta, M. da S.; Mendonça, V.; Soratto, R.P.; Carvalho, L.A. de. Adubação nitrogenada em cobertura no girassol irrigado nas condições de Cassilândia, M.S. Ciência Agrotecnologica, v.32, n.5, p.1366-1373, 2008.

Cunha, P.F.F.C.; Madeiros, L.B.; Alves, W.A.; Dantas Neto, J.; Azevedo, C.A.V.; Beltrão, N.E. de M.; Lacerda, M.D.; Souza, R,M. Níveis de água residuária tratada disponível no solo e nitrogênio:efeito sobre a altura da planta do algodoeiro de fibra marron. In: Congresso Brasileiro de Algodão, 5, 2005, Salvador. Anais..., Salvador: EMBRAPA - Algodão. 2005. CD-ROM.

Farias, C.H. de A.; Espínola Sobrinho, J.; Medeiros, J.F. de; Costa, M da C.; Nascimento, I.B. do; Silva, M.C. de C. Crescimento e desenvolvimento da cultura do melão sob diferentes lâminas de irrigação salinidade da água. Revista Brasileira de Engenharia Agrícola e Ambiental, v.7, n.3, p.445-450, 2003.

Jnad, L., Lesikar, B.; Kenimer, A.; Sabbagh, G. Subsurface drip of residencial effluent: I. soil chemical characteristics. Transaction of the ASAE, St. Joseph.v.44, n.5, p.1149-1157, 2001.

Leal, R.M.P.; Firme, L.P.; Montes, C.R.; Melfi, A.J.; Piedade, S.M.; De S.Soil exachangeable cátions, surgarcane production and nutrient uptake after wastewater irrigation. Science Agriculture (Piracicaba, Brasil), v.66, n.2, p.242-249,March/April 2009.

Raij, B.van; Andrade, J.C.; Cantarella, H. \& Quaggio, J.A. Análise química para avaliação da fertilidade de solos tropicais. Campinas, Instituto Agronômico, 2001. 285p.

Raij, B.van; Cantarella, H.; Quaggio, J.A. \& Furlani, A.M.C., eds. Cana-de-açúcar. In: Recomendações de adubação e calagem para o E stado de São Paulo. 2.ed. Campinas, Instituto Agronômico - Fundação IAC, 1997. p.237-239. (Boletim Técnico, 100).

Sandri, D.; Matsura, E.E.; Testezlaf, R. Características químicas do solo com aplicação de água residuária na cultura de alface por diferentes sistemas de irrigação. Revista DAEE, Ano LX, p.31-39, 2009

Souza, T.M.; Melfi, A.J.; Montes, C.R.; Da Silva, E.; Júnior, S.G.C.; Deon, M.D.; Piveli, R.P. Aporte de nutrientes e estado nutricional da cana-de-açúcar irrigada com efluente de estação de tratamento de esgoto com e sem desinfecção. Revista DAE E, Ano LX, p.17-23, 2009.

Souza, C.C.M.; Bezerra, F.M.L.; Mota, S.; Aquino, B.F.; Avaliação química-bromatológica e produtiva do capim Tifton 85 (Cynodon ssp) irrigado com esgoto doméstico tratado. Revista DAE E, Ano LX, p.24-23, 2009. 